\title{
$X X$. On a systematic interruption in the order of numerical values of vulgar fractions, when arranged in a series of consecutive magnitudes
}

\section{Sir G.B. Airy K.C.B.}

To cite this article: Sir G.B. Airy K.C.B. (1881) XX. On a systematic interruption in the order of numerical values of vulgar fractions, when arranged in a series of consecutive magnitudes, Philosophical Magazine Series 5, 12:74, 175-178, DOI: 10.1080/14786448108627088

To link to this article: http://dx.doi.org/10.1080/14786448108627088

Published online: 17 May 2010.

Submit your article to this journal $[\pi$

Џ Article views: 3

View related articles 


\section{[ 175 ]}

XX. On a Systematic Intermuption in the Order of Numerical Values of Vulgar Fractions, when arranged in a Series of consecutive Magnitudes. By Sir G. B. AIrY, K.C.B., Astronomer Royal*.

GOME years ago I prepared, with the aid of William Ellis, $D$ Esq. (Assistant of the Royal Observatory of Greenwich), the numerical logarithmic values of all the Vulgar Fractions $\frac{m}{n}$, in which $m$ and $n$ are prime to each other and do not exceed 100 ; and arranged them in a Table in order of magnitude of the logarithms. The number of the fractions is 3043. On occasion of introducing this Table at a discussion of the Institution of Civil Engineers, which involved the determination of the number of teeth of wheels required to produce a given proportion of angular speed, the Council of that Institution decided to print the Table in the Selected Papers of their Transactions.

The form of the Table may be understood from the following specimen (taken at hazard):-

\begin{tabular}{|c|c|c|c|}
\hline $\begin{array}{c}\text { Vulgar frac } \\
\frac{64}{\overline{5} 3}\end{array}$ & tion. & $\begin{array}{c}\text { Logarithm. } \\
\cdot 08190\end{array}$ & $\begin{array}{c}\text { Difference. } \\
\cdot 00009\end{array}$ \\
\hline$\frac{93}{77}$ & n................... & $\cdot 08199$ & .00020 \\
\hline$\frac{29}{24}$ & ….............. & .08219 & $\cdot 00023$ \\
\hline$\frac{81}{67}$ & "............... & .08242 & .00011 \\
\hline$\frac{52}{43}$ & ............ & .08253 & $\cdot 00014$ \\
\hline$\frac{75}{62}$ & (........... & $\cdot 08267$ & $\cdot 00007$ \\
\hline$\frac{98}{81}$ & n............... & .08274 & $\cdot 00024$ \\
\hline$\frac{23}{19}$ & ................. & $\cdot 08298$ & \\
\hline
\end{tabular}

The average value of difference for the first 72 fractions is .00010 ; for the following 116 fractions it is $\cdot 00014$; for the next following groups of 116 each, it is $\cdot 00016, \cdot 00016$, $\cdot 00017, \cdot 00018,00019$, and so on, slowly increasing till we come to high numbers. As representing the ordinary range of differences, these numbers are too large, because they include the effect of the special large differences, of which I have now to treat.

* Communicated by the Author.

02 
176 Sir G. B. Airy on a Systematic Interruption in the

In ranging the eye down the columns of differences, it is seen at once that there are some differences much larger than the rest. On close examination, it is seen that they belong exclusively to the Vulgar Fractions whose denominators are small-1,2,3, \&c. I now give the vulgar fractions and the logarithms for several of these instances, accompanied with the fractions next preceding and next following, to show the magnitude of the differences.

Denominator of Vulgar Fraction $=1$.

\begin{tabular}{|c|c|c|}
\hline $\begin{array}{ll}\frac{90}{50} \cdot 29667 & \\
\frac{2}{1} \cdot 30103 & 00436 \\
\frac{99}{49} \cdot 30544 & 00441\end{array}$ & $\underbrace{\frac{3}{1} \cdot 47712}_{\frac{98}{33} \cdot 47272} \cdot 00440$ & $\mid \begin{array}{ll}\frac{99}{25} \cdot 59770 & \\
\frac{4}{1} \cdot 60206 & 00436 \\
\frac{97}{24} \cdot 60656 & 00450\end{array}$ \\
\hline$\frac{99}{\frac{99}{20} \cdot 69461}{ }_{\frac{5}{1} \cdot 69897} \cdot 00436$ & $\begin{array}{ll}\frac{95}{16} \cdot 77360 & \\
\frac{6}{1} \cdot 77815 & 00455 \\
\frac{97}{16} \cdot 78265 & 00450\end{array}{ }^{\circ}$ & \\
\hline
\end{tabular}

Denominator of Vulgar Fraction $=2$.



Denominator of Vulgar Fraction $=3$.

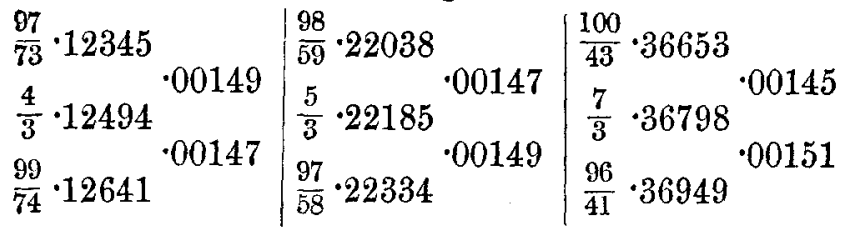

The order of these numbers (which have been examined much further) is sufficiently clear. For the critical or simple values of $\frac{m}{n}$, the logarithmic differences immediately preceding or following these simple values are $\frac{00440}{n}$ nearly. Now .00440 is nearly the logarithm of $1+\frac{1}{100}$. So that the values 
of the three neighbouring fractions in the first instance with denominator 1 are, $2 \times\left(1-\frac{1}{100}\right), 2,2 \times\left(1+\frac{1}{100}\right)$; in the second instance, $3 \times\left(1-\frac{1}{100}\right), 3,3 \times\left(1+\frac{1}{100}\right)$; in the third instance, $4 \times\left(1-\frac{1}{100}\right), 4,4 \times\left(1+\frac{1}{100}\right)$, \&c. And with denominator 2 , the values in the first instance are $\frac{3}{2} \times\left(1-\frac{1}{200}\right), \frac{3}{2}$, $\frac{3}{2} \times\left(1+\frac{1}{200}\right)$; in the second instance, $\frac{5}{2} \times\left(1-\frac{1}{200}\right), \frac{5}{2}$, $\frac{5}{2} \times\left(1+\frac{1}{200}\right)$, \&c. And so for the other denominators. And, between the values thus set down, there is no other value of a vulgar fraction whose numerator and denominator do not exceed 100.

Now the remarkable circumstance attending these large logarithmic differences is, that they all occur in the midst of small differences. Thus we have

$\begin{array}{ccc}\frac{89}{45} & \cdot 29618 & \\ \frac{91}{46} & \cdot 29628 & \cdot 00010 \\ \frac{93}{47} & \cdot 29638 & \cdot 00010 \\ \frac{95}{48} & \cdot 29648 & \cdot 00010 \\ \frac{97}{49} & \cdot 29657 & \cdot 00009 \\ \frac{99}{50} & \cdot 29667 & \cdot 00010 \\ \frac{2}{1} & \cdot 30103 & \cdot 00436 \\ \frac{99}{49} & \cdot 30544 & \cdot 00441 \\ \frac{97}{48} & \cdot 30553 & \cdot 00009 \\ \frac{95}{47} & \cdot 30562 & \cdot 00009 \\ \frac{93}{46} & \cdot 30572 & \cdot 00010 \\ \frac{91}{45} & \cdot 30583 & \cdot 00011\end{array}$

and so for the others. Thus it appears that, though in general 
the most confident reliance may be placed on this Table for finding a vulgar fraction whose value shall very nearly correspond to a given value, yet the particular cases must be excepted in which the given value approaches very nearly to one of the critical fractions, $\frac{2}{1}, \frac{3}{1}, \&$ c. $, \frac{3}{2}, \frac{5}{2}, \& c ., \frac{4}{3}, \frac{5}{3}, \frac{7}{3}, \&$ c. ; and
so for others.

This is the point to which, as the leading subject of this paper, I wished to invite the reader's attention. But, as regards the practical use of the Table, in every case (including all these excepted cases) the Table may be made available for exhibiting two vulgar fractions whose product will exhibit the required number with great accuracy, and that in many different ways. Suppose, for instance, the number to be produced is $2 \cdot 0098$, whose logarithm is 0.30315 . The nearest logarithms in the Table are 0.30103 and 0.30544 , which are far too wide for any accurate purpose. But (among many equally favourable combinations) there is no difficulty in fixing on the tabular numbers $\frac{91}{61}$ whose logarithm is 0.17371 , and $\frac{97}{72}$ whose logarithm is $0 \cdot 12944$. The sum of these logarithms is 0.30315 , as was required; and therefore $2 \cdot 0098=\frac{91}{61} \times \frac{97}{72}$.

On performing numerically the product of these vulgar fractions, it is found to be 2.00979 .

Instead of sum of logarithms of vulgar fractions, difference might be used if it were thought desirable.

Royal Observatory, Greenwich, 1881, August 4.

X'XI. Note on the Laboratory at St. John's College, Oxford. By R. H. M. BosanqueT*.

T $N$ the paper on Beats recently published, the examination 1 of certain simple forms of Beat was described. The then existing arrangements were not free from disturbing noises (engine, shafting, \&c.); and it appeared to me to be a waste of time to proceed further with these investigations until some improvement in this respect could be effected.

A small hydraulic engine was procured and attached to the main supply. The pressure available proved, however, insuffcient, as I had anticipated; and the attemptwas consequently a failure.

Under these circumstances I applied to the College for

* Communicated by the Author, 